\title{
Pensar a epistemologia das Ciências Sociais na contemporaneidade: dilemas de uma ciência incerta
}

\author{
Clóvis Da Rolt \\ Doutorando em Ciências Sociais (Universidade do Vale do Rio dos Sinos)
}

cdrolt@hotmail.com

\begin{abstract}
Resumo Este artigo propõe uma discussão sobre a incursão da ciência na sociedade contemporânea, especificamente no que se refere ao campo das Ciências Sociais. O ponto central do debate está pautado numa revisão de certos aspectos da ciência positivista e em suas disjunções frente às propostas contemporâneas, vinculadas às contribuições da hermenêutica e às abordagens de cunho antifundacional.
\end{abstract}

Palavras-chave: ciência; conhecimento; ciências sociais; epistemologia, sociedade.

$\mathrm{O}$

escritor Octávio Paz conduz a entrada a este artigo mediante uma interrogação que soa pertinente para se pensar a construção de um referencial epistemológico que conduza as atividades da pesquisa científica. Ele admite que a literatura começa quando o escritor suspeita de sua própria condição autoral, permitindo-se, assim, a dúvida: quem fala através de mim quando eu falo? De forma sintética, Paz propõe uma espécie de ruptura diante da ideia da linearidade do pensamento, da expressão e da linguagem humanas, advogando em prol da incerteza e da ambivalência dos caracteres identitários de quem escreve.

Embora este texto não verse sobre literatura, tomo a proposta de Paz como um ponto inicial que pode servir como guia na fixação de linhas teóricas e de conjunturas epistemológicas para a elaboração de um estudo científico, pois acredito que somente por meio da dúvida é que podemos nos aproximar dos contornos daquilo que acreditamos ser o "real". ${ }^{1}$ Desse modo, a desestruturação autoral apregoada por Paz incita à imersão numa postura teórica que pretende validar certos preceitos que não costumam dialogar pacificamente com as posições geralmente monolíticas da atividade científica.

O mundo que nos envolve dá muitos motivos para que desconfiemos de nossa racionalidade e de tudo aquilo que construímos, tendo esse conceito - o de racionalidade - como base. Se, outrora, as relações que moviam o mundo da natureza e o mundo da cultura humana podiam ser explicadas pela intervenção dos mitos, das subjetividades e das diversas formas de religiosidade, a partir do Iluminismo, pelo menos, passou-se a dar um crédito maior à razão como discurso central e substitutivo frente

\footnotetext{
1. Ortega y Gasset (2001, p. 64) adverte que "entre a ideia e a coisa há sempre uma absoluta distância. O real extravasa sempre do conceito que tenta contê-lo. O objeto é sempre mais e de outra maneira que o pensado em sua ideia. Esta fica sempre como um mísero esquema, como um andaime com que tentamos chegar à realidade. Não obstante, a tendência natural nos leva a crer que a realidade é o que pensamos dela, portanto, a confundi-la com a ideia, tomando esta de boa-fé pela própria coisa. Em suma, nosso prurido vital de realismo nos faz cair numa ingênua idealização do real".
} 
a um passado mitificado e impregnado de credulidades que, muitas vezes, a ciência quer nos fazer acreditar que são vergonhosas ou pertencentes a um estágio de barbarismo cultural e de pré-logicidade. ${ }^{2}$ Mas a ciência, não se pode esquecer, também é bárbara em função de seu isolamento, de seu fechamento em si mesma e da pouca capacidade autoanalítica que desenvolveu ao longo de seu desenvolvimento.

A construção de um objeto de estudo científico demanda não apenas a verificação do estado geral em que se encontra uma determinada sociedade ou grupo cultural em relação a uma problemática que se apresenta, mas também um exame profundo das condições de abordagem do discurso científico em relação a essa conjunção de fatores. Em outras palavras, é necessário que se tenha em mente que, a partir do uso dos aparatos conceituais da ciência para a abordagem de um determinado fenômeno, estamos diante de situações que são submetidas a um esquema geral de investigação. Por meio desse esquema, algumas lógicas ou procedimentos são determinados pela tradição da pesquisa e por modelos oficializados e confirmados pelos participantes do campo científico, cujas possibilidades de desvinculação são problemáticas e restritivas.

Desse modo, fazer ciência - ou produzir um conhecimento que passe pelos dispositivos que essa forma de produção intelectual demanda - é depararse com uma estrutura exploratória já pronta e com possibilidades analíticas previamente enquadradas em sistemas lineares, procedimentais, e que atuam mediante etapas consideradas intrinsecamente coerentes devido ao seu uso contínuo e historicizado. Contudo, os procedimentos através dos quais a ciência opera necessitam de constantes revisões, pois não é a crença cega em sua tradição ou em suas sedimentações históricas que garante que sua intervenção tornará um fenômeno mais assimilável, "real" ou compreensível.

Em relação à prática epistemológica aqui proposta - alinhada a uma perspectiva que se poderia qualificar como antipositivista e antifundacional -, é necessário pontuar algumas questões inerentes ao campo da ciência, especificamente em relação às ciências sociais: de que modo e com que autoridade a ciência tomou para si a outorga do caráter de "verdade" aos objetos que investiga? Com base em que princípios o discurso formulado pela ciência alcançou um estatuto valorativamente superior em relação a outras formas de conhecimento e abordagem do mundo dos fenômenos, tanto naturais quanto cultu- rais? Que projeto ideológico subjaz à prática científica, a partir do momento em que ela se propõe a substituir crenças, mitos, valores e saberes dispersos pelo mundo da natureza e da cultura humana por outra forma de compreensão dessas instâncias, se essa forma substitutiva não oferece garantias de que seja a mais apropriada? Para Hekman (1990, p. 24), que tece considerações importantes sobre as questões propostas,

quando os antipositivistas tentam identificar o tipo de conhecimento que é apropriado às ciências sociais, definem-no como um conhecimento "subjetivo", isto é, um conhecimento determinado cultural e socialmente. Esta definição coincide precisamente com o conhecimento "impuro" explorado pela sociologia do conhecimento. A sociologia do conhecimento, despojada da sua metade "objetiva" - o conhecimento puro - torna-se o instrumento perfeito de uma metodologia antipositivista. Permite aos antipositivistas explorar as bases sociais do conhecimento e argumentar que esta exploração não resulta na acumulação de "conhecimento objetivo" característica das ciências naturais.

Os problemas que advêm das polarizações relativas aos enfoques das ciências naturais e das ciências culturais estão longe de chegar a um denominador comum, já que a persistência nas divisões sumárias ainda compõe uma forma eficaz de estruturação do mundo do conhecimento científico e de sua inserção na esfera acadêmica. Numa perspectiva antifundacional, corre-se sempre o risco de sofrer a acusação de falta de "rigor científico", displicência metodológica e demasiada liberdade em interpretações não compartilhadas entre os atores sociais que movem a esfera científica. Geertz (2001, p. 127) expõe esse combate em palavras contundentes ao alegar que uma das coisas mais irritantes em seu campo

são as pessoas que dizem que não se está fazendo "ciência de verdade" quando não se formula nenhuma lei, com isso sugerindo que elas as formularam, mas sem nos dizer, na verdade, quais são essas leis. Nas raras ocasiões em que elas nos dão essa informação [...] a situação fica pior. $\mathrm{O}$ cientificismo - e, nesse caso, quero falar das ciências humanas em geral - é quase sempre um blefe.

As bases teóricas tomadas para discutir a situação dos conflitos epistemológicos atuais ganham em profundidade e dinamismo quando atreladas ao pen-

2. Vattimo (2006, p. 113) afirma que "o mito não é um pensamento demonstrativo, analítico, etc., mas sim narrativo, fantástico, coimplicante das emoções e globalmente com pouca ou nenhuma pretensão de objetividade; [...] a ciência nasce, justamente ao contrário, como desmistificação, como 'desencantamento do mundo'." Em espanhol no original: "El mito no es un pensamiento demostrativo, analítico, etc.; sino narrativo, fantástico, coimplicante de las emociones, y, globalmente con poca o ninguna pretensión de objetividad; [...] la ciencia nace, justamente al contrario, como desmitificación, como 'desencanto del mundo'." (Tradução livre). 
samento de Santos (1989), que alega que a crise do paradigma da ciência moderna surge concomitante a uma crise epistemológica. Esclarece que seu ponto de partida é uma revisão estrutural da construção epistemológica bachelardiana, a partir da qual, advoga em prol do desenvolvimento de um projeto científico marcado por uma atitude hermenêutica (Santos, 1989, p. 30). Assim, o autor aponta para uma necessária revisão das práticas constitutivas da ciência na atualidade, numa atitude que permita compreender mais profundamente seu modus operandi, de modo que o conhecimento científico seja uma parte integrante da sabedoria prática (phronesis) de que dispomos para organizar a vida em sociedade. O recurso à hermenêutica assume papel central, pois é ele que permite amenizar a incomunicabilidade da ciência com outras formas de discurso consideradas menos herméticas, como é o caso do discurso religioso, estético e do senso comum (Santos, 1989, p. 12).

O que está no centro da reflexão epistemológica de Santos é a dimensão social do conhecimento científico e sua efetiva compreensão, já que o legado da ciência moderna foi estritamente unidimensional ao encarar os fenômenos da realidade mediante métodos e posições teóricas excessivamente abreviadores. Por meio da aplicação dos dispositivos avaliativos da hermenêutica sociológica à epistemologia, Santos pretende esclarecer que toda ciência é social a partir do momento em que se admite que ela é produzida "na" e "para" a sociedade. Essa perspectiva traduz o conhecimento científico como uma atividade mediada pelos condicionamentos históricos da própria sociedade, dos quais ele é produto. É a atitude hermenêutica, revela Santos (1989, p. 13), que faz compreender a ciência como "prática social de conhecimento, uma tarefa que se vai cumprindo em diálogo com o mundo e que é, afinal, fundada nas vicissitudes, nas opressões e nas lutas que o compõem."

A ciência moderna engavetou o conhecimento numa série de especializações, pois sua atitude diante dos objetos investigados obedecia a um princípio reducionista, segundo o qual o cognoscível estava diretamente ligado ao manipulável. A orientação da prática científica moderna é de cunho essencialmente normativo, ou seja, trata-se de uma orientação que se esforçou em imprimir um modo dogmático de apreensão do real. Nas figuras de Bacon, Newton e Descartes, essas características da ciência moderna estão inseridas em filosofias que apontam para uma avaliação da dupla via legitimadora do conhecimento: a empiria e o método.

As consequências da orientação utilitarista, mecanicista e racionalista da ciência moderna renderam e ainda rendem diversas matrizes de reflexão epistemológica. A principal abordagem encontrada em diversos pensadores e críticos da ciência refere-se à centralidade que o modelo racional estabeleceu como parâmetro para validar, mediante posturas arbitrariamente conclusivas, diferentes práticas humanas. O ápice resultante das concepções racionalistas da ciência pode ser verificado no eixo do positivismo científico, em torno do qual gravitam certas condições gerais que sustentam a prática científica: a) a realidade é incontestavelmente dotada de exterioridade; b) o conhecimento é a representação fidedigna do real; c) opera-se um dualismo entre fatos e valores com a implicação de que o conhecimento empírico é logicamente discrepante dos valores morais e, portanto, negligencia qualquer abordagem ética -; e d) admite-se a noção de "unidade da ciência", nos termos da qual tanto as ciências naturais quanto as ciências sociais partilham uma mesma fundamentação lógica e metodológica (Santos, 1989, p. 52).

Tais premissas parecem sucumbir lentamente a uma produção científica que aposta num paradigma mais preocupado com um conhecimento prudente e auxilie a humanidade em tudo aquilo que pode torná-la menos sofrível, individualista e desencantada. Uma nova atitude científica, da forma como a concebe Morin, deve considerar que a ciência, como a sociedade, passa por revoluções, dando saltos ontológicos de um universo para outro. Por isso mesmo, para Morin (1996, p. 56-58), "a ciência sustenta-se como um jogo onde não há verdade, porque a ciência não comporta a verdade. Não existe uma verdade científica, existem verdades provisórias que se sucedem, onde a única verdade é aceitar essa regra", pois "o conhecimento científico é contraditório e é ingênuo crer que ele é um reflexo puro do real".

Se, por um lado, a formalização moderna de um sistema conceitual e abstrato, capaz de produzir conhecimentos que ofereçam respostas às indagações humanas, é considerada motivo de júbilo frente às capacidades intelectuais do homem, por outro lado, ela também converte-se num motivo de constantes interrogações: a ciência é capaz de oferecer respostas socialmente abrangentes, inclusivas, e que possam ser assimiladas por todos, indistintamente? Faz parte de um anseio consciente, por parte de todo o mundo social atual, que a ciência seja a forma representativa da verdade e do real? Se considerarmos as muitas formas, impulsos e impactos com que tanto a verdade quanto o real podem agir no íntimo de cada ente humano, como aceitar o caráter decisório e arrogante da ciência sempre que ela se propõe a falar em nome da "natureza" ou do "ser humano", se essas são categorias que ela não tem condições de conhecer na totalidade?

Nas palavras de Morin (1996, p. 20), esses aspectos ficam claros quando o autor sugere que a ciência não controla sua própria estrutura de pensamento, isto é, "o conhecimento científico é um conheci- 
mento que não se conhece.” E, devido à extensão do seu anonimato, o conhecimento científico é um conhecimento que não tem condições de postular que o seu modo particular de demonstrar, argumentar e apresentar leituras do mundo dos fenômenos seja o mais coerente ou o mais seguro. Ortega y Gasset (2001, p. 37) dinamiza essas considerações ao propor que "a ciência se esforça para descobrir o ser inesgotável que constitui a vitalidade de cada coisa. Mas o método que emprega cobra uma exatidão à custa de não conseguir nunca todo o empenho." $\mathrm{E}$ isso acontece porque

cada coisa concreta é constituída por uma soma infinita de relações. As ciências procedem discursivamente, buscam uma a uma essas relações, e, portanto, necessitarão de um tempo infinito para fixar todas elas. Esta é a tragédia original da ciência: trabalhar para um resultado que nunca logrará plenamente. (Ortega y Gasset, 2001, p. 39)

No bojo das muitas contradições que sustentam a atividade científica, não podemos nos esquecer de que ela está contida no universo da cultura humana e que, por isso mesmo, responde a interesses humanos, ${ }^{3}$ histórica e socialmente posicionados. Para Ortega y Gasset, os espaços da cultura e da história, de onde brota a ciência, apontam para inúmeros retrocessos, decadências e degenerações. É com vistas a esse registro dramático da história humana que devemos olhar para a ciência, pois

a sorte da cultura, o destino do homem, dependem de que, no fundo de nosso ser, mantenhamos sempre viva esta dramática consciência e, como um contraponto murmurante em nossas entranhas, sintamos bem que, para nós, só é segura a insegurança. (Ortega y Gasset, 1973, p. 65)

Devido à condição de incerteza substancial que nos configura como entes humanos, somos cerceados pela noção geral de que não existe aquisição humana que seja suficientemente firme, isto é, mesmo aquilo que julgamos consolidado pode desaparecer em poucas gerações. O mundo e a realidade são o mundo e a realidade para mim. A ciência não tem condições de alcançar a intimidade individual de cada ente humano. Seus métodos, formas e técnicas de investigação são demasiadamente pobres para criar imagens globais que representem "o homem" ou "a natureza" para mim e que, ao mesmo tempo, sejam capazes de incluir-me nas apropriações que outros indivíduos fazem dessas imagens.

A dúvida de que as diversas linguagens que o ser humano desenvolve sejam, de fato, adequadas, poucas vezes é exercitada, o que vale também para os diversos ramos da ciência. Certamente, quem exercita tal dúvida (o que vale para os investigadores sociais) não está incluído nos substratos desfigurados pela massificação cultural e pela paralisia do pensamento, visto que, provavelmente, ocupa posições privilegiadas na produção de um saber referendado por seus pares e por instituições que o reproduzem e garantem sua legitimidade, como é o caso das universidades e centros de pesquisa.

Assim, é necessário que haja clareza de que os conceitos, as conjunturas socioculturais, as percepções sobre os atributos que dicotomizam a esfera da natureza e a esfera da cultura ${ }^{4}$ (muitas vezes de forma infundada), bem como os valores que permeiam a pesquisa científica, não são de domínio ou conhecimento universais. Esse aspecto aponta para uma reflexão urgente, mediante a qual é preciso considerar que o conhecimento não tem dimensões totalizantes na sua produção e muito menos na sua disseminação ou apropriação social. É como se, grosso modo, nós, pesquisadores, estivéssemos enraizados numa ilha enquanto produzimos nossos conhecimentos, os quais nós engarrafamos e lançamos ao mar para, quem sabe, a garrafa ser aberta numa outra ilha, por habitantes que nos desconhecem.

As pessoas, de um modo geral, convivem muito bem sem ter a consciência de que suas vidas estão impregnadas de ciência. Não é raro que alguns lampejos de consciência sobre a incursão da ciência em suas vidas ocorram de modo caricaturizado e esquematizado, pois a ciência, bárbara como é, não sabe dialogar com quem não domine os códigos e as estruturas conceituais por meio dos quais ela assume sua personalidade grandiloquente. Dominar o discurso científico equivale a dominar os códigos das linguagens nas quais ele se inscreve. A ciência deve permitir formas de recriação do conhecimento que elabora, pois é por meio da recriação que o conhecimento científico se abre à coletivização. $\mathrm{O}$ pano de fundo da discussão de Bronowski (1983, p. 34) está centrado na noção de que a ciência é também uma atividade envolvida por uma dimensão estética e, portanto, impregnada de um caráter imaginativo. Para esse autor, "a imaginação é a manipulação no espírito de coisas ausentes, utilizando em seu lugar imagens, palavras ou outros

3. Habermas possui um texto esclarecedor sobre a ação da categoria do "interesse" na produção do conhecimento científico. Ver Habermas (1980, p. 301-312)

4. Sobre esta problemática cisão entre natureza e cultura, sugiro a leitura de Bateson (1997). Nesta obra, a investigação de Bateson concentra-se na relação entre natureza e cultura, mediante um elo de ligação que o autor denomina "pauta conectiva". Trata-se de uma busca de relações íntimas entre o biológico e o social como instâncias autoimplicadas uma na outra, cujo resultado é um mundo interatuante e não-categorizável. 
símbolos”. Prosseguindo seus apontamentos, Bronowski (1983, p. 36) diz que

um físico faz experiências com situações materiais cujas propriedades não conhece totalmente e um poeta tenta encontrar o seu caminho através de situações humanas que não compreende integralmente. Ambos estão a aprender através da experiência. E ambos estão a fazer experiências com situações que têm de imaginar antes de as poderem criar.

A ciência goza, atualmente, de diferentes e conflitantes estatutos. Para algumas pessoas, ela é vista como uma atividade altamente influente, realizada por cientistas trancafiados em laboratórios e empenhados em oferecer respostas seguras para diversos fenômenos. Para outras pessoas, a ciência não pode ser neutra, porque ela está cercada pelas variações políticas e ideológicas que configuram uma determinada época e, por isso mesmo, deve suscitar mais suspeitas do que confiança. Por fim, para um grande contingente de pessoas, a ciência é uma atividade da qual se toma conhecimento pela televisão, quer seja pela figura estereotipada do cientista com olhos esbugalhados, gestos desajeitados e cabelos espaventados dos filmes produzidos pela indústria do entretenimento, quer seja pelas representações dos telejornais, quando estes mostram as cenas de um astronauta fazendo reparos em uma estação espacial, um clone produzido a partir de algum animal ou um transplante de coração bem-sucedido. Desprovidas de um adequado aparato de conceitos e de categorias de análise necessárias à avaliação do que veem, as pessoas se seduzem com o fato de que a ciência seja capaz de feitos tão grandiosos, ainda que não tenham a mínima noção de que a ciência é uma faca de dois gumes, e de que aquilo que presenciam pela televisão pode ser o prenúncio de diversas formas de violência, segregação e desigualdade social. Atado a essas multifocalizações nos usos sociais da ciência pós-moderna, Santos (1989, p. 27) esclarece que, "de um ponto de vista sociológico, o discurso científico é hoje, em face do cidadão comum, um discurso anormal no seu todo".

Retomando o aforismo inicial de Paz, pode-se relacioná-lo ao momento histórico em que vivemos, em que a sociedade como um todo não mais se apresenta sustentada pelos valores que administraram uma série de condutas, aspirações e entrelaçamentos da práxis humana ao longo da modernidade. E os valores, como se sabe, são áreas de inexatidão e incerteza que, talvez, participam com mais ênfase na construção daquilo que denominamos "sociedade." Os valores são viscerais, um misto de consciência e instinto impregnado de paixões e subjetividades. Para Castoriadis (2009, p. 11), os valores - frutos de uma paideia que se desenvolve ao logo da vida de que cada indivíduo - "não são dados por uma instância externa, nem descobertos pela sociedade em camadas naturais ou em um céu da Razão”. Eles são, em todas as ocasiões, "criados pela sociedade considerada como núcleo de sua instituição, baliza última e irredutível da significação, polos de orientação do fazer e do representar social" (Castoriadis, 2009, p. 11) A ciência esforça-se por anular e expulsar de sua prática a humanidade essencial dos valores, como se eles fossem entidades nefastas à produção da "verdade" científica que não sabe conviver com as contradições. Como diz Morin (1996, p. 43), não existem fatos puros, mas tão somente uma seleção de fatos intrinsecamente dependentes dos instrumentos e das ferramentas materiais do conhecimento, bem como dos instrumentos mentais que são os conceitos. Nessa mesma linha, Santos (2003, p. 56) ensina que os objetos que tomamos como fontes de elaboração científica "têm fronteiras cada vez menos definidas; são constituídos por anéis que se entrecruzam em teias complexas com os dos restantes objetos, a tal ponto que os objetos em si são menos reais que as relações entre eles".

Segundo Pessanha ([s.d], p. 18), a clareza dos conceitos através dos quais nos movemos para produzir o conhecimento é uma utopia. O autor aborda essa questão ao referendar que somos vítimas de uma espécie de "mito da clareza", em torno do qual foi construída grande parte da modernidade, um mito que trouxe consigo a ideia da "identidade com $i$ maiúsculo, da unidade com um $u$ imenso e da verdade com um $v$ gigantesco". Não se pode dar as costas ao fato de que os conceitos - aos quais associaríamos as diversas teorias científicas e a própria epistemologia - são unidades de linguagem em desenvolvimento e, portanto, em transformação. E tudo que se transforma traz em seu âmago o gene da ruptura e da contingência, o que nos leva a trazer para o centro do nosso debate uma premissa fundamental da filosofia de Nietzsche, a qual estabelece que não há fatos, há somente interpretações. Assim, advoga-se aqui em prol de um circuito de produção e distribuição do conhecimento científico de cunho interpretativo, que compactua com a "atitude hermenêutica" de que nos fala Santos. ${ }^{5}$ Trata-se de uma atitude que encara o

5. Além da perspectiva hermenêutica evocada por Boaventura de Sousa Santos como base das investigações em ciências sociais, é importante lembrar o ponto de vista pioneiro de Mannheim sobre essa questão. Hekman (1990, p. 126) adverte que "a filosofia das ciências sociais 'sem fundamento' que Mannheim propõe oferece um conjunto de vantagens evidentes para as ciências sociais. Em primeiro lugar, de um modo mais claro do que qualquer outro sociólogo do conhecimento, Mannheim define a tarefa das ciências sociais como interpretação hermenêutica. Ainda que outros na sua época (por exemplo, Weber e Simmel) salientem o papel interpretativo das ciências sociais, Mannheim é mais explícito sobre o procedimento hermenêutico implicado nas investigações realizadas nas ciências culturais". 
conhecimento como uma forma social de reconhecimento humano.

Há cerca de cem anos, Simmel escrevia que pretender uma plenitude sistemática, no plano científico, poderia ser uma forma de enganar a si mesmo. Longe de fixar uma atitude científica de caráter dogmático, Simmel talvez seja uma das figuras essenciais que, partindo de concepções originais em relação ao estudo da sociedade, proporá a desagregação e a descontinuidade como processos altamente significativos, bem como atentará às dinamizações de tempo, de espaço, de articulação e de propósito naquilo que permite identificar sociações e intercâmbios interacionais. Isso porque, para Simmel, nem tudo, na prática científica, pode ser previsto ou determinado de antemão, visto que o próprio fazer científico é que, muitas vezes, vai determinando as condições efetivas de sua elaboração. Assim, Simmel (1983, p. 70) sugere que a prática científica "não pode prescindir de certo procedimento instintivo, cujos motivos e normas somente depois chegam totalmente à clara consciência e elaboração sistemática". Numa interpretação bastante pessoal dos critérios simmelianos de seleção e abordagem de um objeto investigativo, fica visível que sua forma fragmentária de encarar os fenômenos sociais não está voltada para a fixação de grandes sínteses ou de cenários conjunturais, mas, pelo contrário, procura traçar quadros localizados em que o indivíduo encontra-se imerso em circuitos de ações que, ora o absorvem, ora o repelem.

As dinâmicas que subjazem a um estudo de natureza social são diversas e não se resumem facilmente a uma delimitação esquemática do que se pode compreender por "social". Por mais que se tente vedar o conceito, cercando-o por meio de barreiras lógicas e estritamente adequadas a uma abordagem científica, ainda assim é preciso admitir que se trata de um conceito. Assim, tomando novamente o pensamento de Morin, percebe-se que esse autor questiona a "cientificidade" das Ciências Sociais, sobretudo da Sociologia, ao alegar que as "leis" sociológicas são vagas e triviais e que suas condições de verificação são limitadas e duvidosas. O ponto central desse debate é o que o autor chama de "indecidibilidade" das ciências, pois elas são pautadas em sistemas conceituais, e um sistema conceitual precisa de um metassistema que o avalie, numa sucessão que se estenderia ao infinito. É muito comum ocorrer associações entre o progresso científico e a ideia de racionalidade, ordem e organização. Por uma ótica da complexidade, ${ }^{6}$ contudo, pensa-se o progresso como incerteza, negação e degradação potencial. Nesse sentido, o progresso dos conhecimentos especializados que não se comunicam uns com os outros provoca a regressão do conhecimento geral (Morin, 1996, p. 99).

Tomando a problemática noção de "consciência histórica" como uma categoria arraigada nos debates sobre a cultura contemporânea, creio ser possível equacionar as aspirações de Morin no que diz respeito a uma nova prática científica que parte da incerteza, sem olhar para o passado como o porto seguro para onde sempre se pode voltar a atracar em busca das "origens", dos "princípios" e dos "fundamentos". Gadamer (2003, p. 17) ensina que "a consciência histórica é o privilégio do homem moderno de ter plena consciência da historicidade de todo presente e da relatividade de toda opinião". Aliado a essa mesma percepção, Vattimo (2006, p. 80) também prescreve uma abordagem científica que remete à quebra dos fundamentos consensuais enraizados na ciência positivista, pois

não só em comparação com outros universos culturais ( o "terceiro mundo", por exemplo), mas também visto de dentro, o Ocidente vive uma situação explosiva, uma pluralização que parece irrefreável e que torna impossível conceber o mundo e a história segundo pontos de vista unitários.

Uma postura epistemológica pautada na noção de formatividade sugere que, a cada novo passo de um processo investigativo, um jogo entre clareza e obscuridade vai tecendo a trama dos conceitos, das ideias, das referências e das mediações com as quais nos defrontamos. É por meio dessa atitude que $\mathrm{Pa}$ reyson (1993, p. 177) descreve a condição humana inscrita na prática de "formar", "dar forma", pois "a mobilidade indefinida e a histórica desenvolvibilidade do homem não passam de plasticidade, que tende a plasmar-se em formas e a plasmar formas: mobilidade que é esforço de formação, ímpeto de plasmação, elã de figuração". Mediante tal postura investigativa, o processo de imersão em situações cognoscíveis é alavancado pela incerteza em relação ao devir dos acontecimentos, sobretudo pela presença da formatividade como resultado de interpretações que se inscrevem no ato de construir a si próprias, mediante a matéria existencial que lhes serve de circunstância. Desse modo, Pareyson (1993, p. 175) sustenta que

a interpretação é justamente isto: mútua implicação de receptividade e atividade. Com efeito, a atividade desencadeada para interpretar é a adoção do ritmo do objeto. A interpretação por um lado é ressonância do objeto em mim, ou seja, receptividade que se prolon- 
ga em atividade, dado que recebo e, ao mesmo tempo, desenvolvo; e, por outro lado, é sintonia com o objeto: um agir que se dispõe a receber, um fazer falar para escutar, atividade em vista de uma receptividade. A interpretação é um ver que se faz contemplar, e um contemplar que visa ao ver.

A ciência vista como um ato interpretativo é o que pode ser extraído das tendências antipositivistas que sugerem novas formas de abordagem dos fenô- menos naturais e culturais. Por meio dessa leitura, tais fenômenos não ocorrem como manifestações acopladas a um ideal de superação histórica, obstinado por patamares sempre ascendentes. O mundo é tanto uma instância interna quanto externa ao homem e é por meio desse duplo registro que se pode falar na autoria do ato interpretativo como algo que não visa à instituição e ao enquadramento do "fato", mas de sua manifestação em meio aos diversos conflitos que caracterizam a história da humanidade.

\title{
Referências
}

BATESON, Gregory. Espiritu y naturaleza. Buenos Aires: Amorrortu Editores, 1997.

BRONOWSKI, Jacob. Arte e conhecimento: ver, imaginar, criar. São Paulo: Martins Fontes, 1983.

CASTORIADIS, Cornelius. Janela sobre o caos. Aparecida: Ideias e Letras, 2009.

GADAMER, Hans-Georg. O problema da consciência histórica. Rio de Janeiro: Editora FGV, 2003.

HABERMAS, Jürgen. Conhecimento e interesse. In: Textos escolhidos: Walter Benjamin, Max Horkheimer, Theodor Adorno e Jürgen Habermas. São Paulo: Abril Cultural, 1980.

HEKMAN, Susan J. Hermenêutica e sociologia do conhecimento. Lisboa: Edições 70, 1990.

MORIN, Edgar. O método I: a natureza da natureza.Porto Alegre: Sulina, 2003.

. Ciência com consciência. Rio de Janeiro: Bertrand
ORTEGA Y GASSET, José. Adão no paraíso e outros ensaios de estética. São Paulo: Cortez, 2002.

O homem e a gente: inter-comunicação humana. Rio de Janeiro: Livro Ibero-americano, 1973.

PAREYSON, Luigi. Estética: teoria da formatividade. Petrópolis: Vozes, 1993.

PESSANHA, José Américo. Filosofia e modernidade: racionalidade, imaginação e ética. Cadernos ANPEd, n. 4, [s.d]. (Conferências da $15^{\mathrm{a}}$ Reunião Anual).

SANTOS, Boaventura de Sousa. Um discurso sobre as ciências. São Paulo: Cortez, 2003.

Introdução a uma ciência pós-moderna. Rio de Janeiro: Graal, 1989.

SIMMEL, Georg. Sociologia. São Paulo: Ática, 1983.

VATTIMO, Gianni. La sociedad transparente. Barcelona: Paidós, 2006.

Brasil, 1996.

\section{Thinking the epistemology of Social Sciences in contemporary age: dilemmas of an uncertain science}

\begin{abstract}
This paper proposes a discussion about the incursion of science in contemporary society, specifically with regard to the field of Social Sciences. The focus of the discussion is guided by a review of some aspects of positivist science and its disjunctions in the face of contemporary proposals, linked to the contributions of hermeneutics and anti-foundational approaches.
\end{abstract}

Key-words: science; knowledge; social sciences; epistemology; society. 


\section{Pensar la epistemología de las Ciencias Sociales en la contemporaneidad: dilemas de una ciencia incierta}

\section{Resumen}

Este artículo propone una discusión acerca de la incursión de la ciencia en la sociedad contemporánea, con particular atención al campo de las Ciencias Sociales. El foco de la discusión se guía por una revisión de algunos aspectos de la ciencia positivista y sus separaciones de las propuestas contemporáneas, vinculadas a la contribución de la hermenéutica y de los enfoques que luchan contra las tesis fundacionales.

Palabras-clave: ciencia; conocimiento; ciencias sociales; epistemología; sociedad.

Data de recebimento do artigo: 17/01/2011

Data de aprovação do artigo: 22/05/2011 